Original Research Paper

\title{
A Prescriptive Specialized Learning Management System for Academic Feedback towards Improved Learning
}

\author{
Annette van der Merwe, Tiny du Toit and Hennie Kruger \\ School of Computer Science and Information Systems, North-West University, Potchefstroom, South Africa
}

Article history

Received: 02-07-2018

Revised: 13-09-2018

Accepted: 20-10-2018

Corresponding Author: Annette van der Merwe School of Computer Science and Information Systems, North-West University, Potchefstroom, South Africa Email: annette.vandermerwe@nwu.ac.za

\begin{abstract}
The dynamic nature of technological advances is causing changes in many fields and especially in tertiary education. Student numbers are increasing annually and institutions need to maintain education quality whilst ensuring student retention. A specialized learning management system (SLMS) was developed in this study that provides students with comprehensive feedback which will enable them to better manage their academic performance. It will also assist institutions/lecturers in identifying at-risk students early in a semester to facilitate retention. The system uses a prescriptive analytics engine implemented by means of mathematical modelling techniques together with an algorithmic approach to process academic student data in realtime. Feedback is delivered timely and is comprehensive in the sense that it presents students with individualized instructions towards improvement in a module. The system was implemented in a field test and evaluated according to validation criteria established from a literature study on related research efforts. A survey was conducted to measure user response in terms of the identified factors. The results showed that the SLMS conforms to the attributes essential to an action-recommender system and was favorably accepted by the target users.
\end{abstract}

Keywords: Academic Feedback, Learning Analytics, Specialized Learning, Management System

\section{Introduction}

The success of education is determined by various factors with an institution, a faculty and students all playing contributing roles towards reaching this goal. The face of education is changing due to new teachinglearning techniques being implemented on a variety of different platforms. A troubling yet consistent pattern that has been observed in education, is the simultaneous decline of student motivation and engagement over the progression of a school year (Patall et al., 2018). A similar pattern has been recognized in student participation in academic activities at tertiary institutions (Du Toit, 2015). An activity as simple as attending classes, for example, is a greater predictor of possible tertiary academic success than high school grades (Carroll and St. Peter, 2017). The benefits for students in attending classes are obvious but lecturers need to change the ways in which they teach and assess by incorporating new technological advances into their teaching methods so as to also motivate them to participate in academic activities
(Massingham and Herrington, 2006). This plays an integral role in the employability development of students (Jepson and Ryan, 2018).

Academic motivation is an enactment of a person's will to attend classes, partake in discussions and endeavor to learn and achieve success in their studies (Beck, 2004). Studies show that the implementation of self-monitoring initiatives in mainstream classrooms result in increases in students' participation and subsequent academic achievement (Rock, 2005). Students who try to selfregulate their studies display responsibility in terms of controlling and performing actions relating to their studies (Garcia, 1996). Also, students that self-motivate exhibit a sense of self-management and achieve greater academic success (Di Domenico and Fournier, 2015).

Continuous new developments in computer technology has had an impact on education in the sense that activities are gradually becoming more dependent on the Internet (Fındık-Coşkunçay et al., 2018). This has led to the emergence and growth of e-learning wherein course material and various other resources are made 
available to learners over the Internet. One of the most commonly used types is a Learning Management System (LMS) which is generally used to administer, document, track, report and deliver educational resources and assessment material. LMSs implement learning analytics tools that can be functional for creating student activity profiles from their digital footprints, thereby assisting lecturers and institutions with various administrative tasks. Many of these systems perform very specific tasks like talent management (Bersin, 2015) or Software-as-aService (SaaS) learning management (Lin, 2015). Such systems are referred to as specialized Learning Management Systems (SLMS) because they perform specific actions within an exact field and towards explicit goals. A LMS that simply provides statistics on student resource use, will not have such a motivating effect on students. An SLMS however, will not only inform students on their current academic performance but will also provide them with ways to improve towards the close of the semester (term). Such an SLMS will require specialized information like the number and formats of the assessments planned for a semester and utilize techniques, like mathematical modelling and learning analytics to continuously create improvement plans for individual students, based on their current performance. The resulting SLMS can be considered an action-support recommender system (Kaklauskas et al., 2013) which will assist students in deciding what actions to take in order to improve their academic standings.

Learning analytics as a research field describes the measurement, collection, analysis and reporting of learner data and can be used to determine which students appear to be at risk of failing a course (Sclater et al., 2016). Research of the incorporation of such analytical tools into an SLMS, the extent of usefulness towards the learning experience as well as the way in which the information is reported, remain a concern. There are specific issues that need to be addressed when academic feedback is presented to students and lecturers (Van der Merwe et al., 2018a). Although feedback is essential to the improvement of learning, it needs to be provided in such a way that it is correctly interpreted by the users (Lee, 2018). This can be done effectively through development of an ideal SLMS interface to use for presentation of properly formatted feedback.

The main problem is that although technology advances have caused an increase in student enrolment numbers, the retention rates remain low. The research question of this study is therefore to determine if an SLMS that uses mathematical modelling and learning analytics techniques can improve learning and the subsequent student retention rates.

Research and development of a specialized product in education that has the purpose to improve learning, are typically done according to specific phases as described by Darmawan et al. (2018). The phases are discussed in concurrent sections in this study which commenced with problem identification in the introduction. This will be followed by a literature study on current work relating to the use of LMSs, learning analytics, feedback in the academic environment and software development in the next section. The development of the SLMS is discussed in the section titled "Method" in which evaluation criteria for system validation is also outlined. A field test in the form of a case study and deficiency corrections is then discussed in "Field testing". This is followed by a discussion on the research findings and the paper closes with concluding remarks.

\section{Related Work}

Due to the special nature of an SLMS, its evaluation criteria cannot be limited only to that of a LMS. Consideration needs to be given to the methods implemented to perform special functions as well as the output it provides. Therefore, the SLMS must be evaluated against the criteria for a LMS and specialized learning analytics that provide output towards actionsupport recommendations.

The frequency of use of a LMS by end-users gives an indication of how successful it has been implemented. To properly evaluate the user satisfaction level when using LMSs, Almarashdeh et al. (2018) investigated the factors that influence students' satisfaction with LMSs in tertiary education programs. These factors were taken into consideration in establishing evaluation measures for user satisfaction of the SLMS developed in this study. These measures are outlined in the next section.

Learning analytics is a concept that describes the collective processes applicable when working with large quantities of student data (Dietz-Uhler and Hurn, 2013). It is traditionally implemented as part of a LMS and used to provide information regarding individual students' use of specific resources supplied to them by a lecturer (Yulianto et al., 2018). Researchers demonstrate differing perceptions on the use of learning analytics and its usefulness for improved learning (Ellis et al., 2017). There is concern regarding the interpretability of learning analytics in terms of what it indicates about student activity as opposed to measuring the quality of learning that is actually taking place (Ellis et al., 2017). Various investigations have been done to improve one or more of the phases (measuring, collecting, analyzing and reporting) of learning analytics for the purpose of improving the type of information available to both the lecturer and the student (Hernández-Lara et al., 2018; Schumacher, 2017; Van der Merwe et al., 2018b; Yulianto et al., 2018). By combining learning analytics with data mining techniques, valuable information relating to students who appear at risk of failing the program, curriculum structures and prediction of 
academic performance, can be gained. Lecturers typically use learning analytics to identify students who do not actively access the resources given so that they can intervene at an early stage during the program and prevent students from falling behind. However, depending on the type of material shared on LMSs, such information does not necessarily present an accurate estimate of which students are at risk of failing.

Daniel (2015) argues that to effectively improve learning, specialized learning analytics in the form of prescriptive analytics is also required. This form of learning analytics enables a decision maker (the student) to gain perspective on specific actions that need to be performed in the near-future in order to improve learning. Data must be collected consistently throughout the learning process and implemented to create a structure which will enable a student to make informed choices on alternate actions of participating in academic events, based on valid predictions. Academic data can be analyzed in this way to create a personalized learning experience for each student (Daniel, 2015). Ellis et al. (2017) found that there were some concerns relating to data collection and interpretation as part of learning analytics and they worked to combine observational and self-report data towards finding a solution. Suthers and Vebert (2013) stated that learning analytics methods should be supplemented with techniques that provide more comprehensive information on the extent of student success.

Implementing learning analytics to keep students informed of their academic performance can improve student retention rates (De Freitas et al., 2015). An academic status report can be compiled from the grades that a student achieved in all of the formative assessments completed, from the very start of a semester up to the present. Such assessments can include formal tests, informal tuition tests, practical assignments or even class attendance. For each of these groups, an average mark is typically calculated which contributes a certain percentage towards a participation mark. A participation mark represents a student's level of participation in academic activities throughout a semester and can be used to determine whether a student is allowed to take the final examination. Van der Merwe et al. (2018b) presented the use of mathematical modelling techniques to perform data analyses on student data in order to generate and produce academic status reports. A linear programming model was utilized to determine, for each individual student, the weight distribution for each of the assessment groups that would result in a minimum and maximum participation mark, provided that the weights remain within predetermined limits. For the formulation of the linear program, refer to Appendix A. An academic status report at a specific point in time during a semester typically consists of the group averages that a student has achieved up to that stage, the current minimum participation mark and ranking level that informs the student how he/she is progressing in relation to the rest of the class. Furthermore, an algorithm was developed to generate an individualized improvement plan for each student as well as targets towards the calculated improvement. The algorithm is available in Appendix B. The research embodies the combination of learning analytics with mathematical programming techniques as prescriptive analytics. The resulting academic performance profiles created for students, conformed to the three requirements for feedback to be effective which include feed-backwards (a current performance status report), feed-upwards (improvement goal) and feed-forward (activities to be performed towards reaching the improvement goal) as set by Hattie and Timperley (2007). Detailed discussions of the models can be found in Van der Merwe et al. (2018b). The feedback must be presented to either a student or lecturer user in such a way that the best choice of action(s) for improved learning can be made easily. Towards this end, Jameson et al. (2014) created a set of criteria for an action-support recommender system, which were considered to establish evaluation measures for the SLMS developed in this study.

The SLMS created in this study is a specialized LMS, uses learning analytics techniques and provides academic feedback in a user-friendly interface. This section presented a brief introduction on recent work in these research fields towards setting criteria for evaluating the SLMS. These criteria are stated in the next section, followed by a presentation of the developed system.

\section{Method}

This study was conducted according to the positivistic paradigm for Information Systems (Siponen and Tsohou, 2018). An action design research method was used to develop the SLMS which was implemented in a case study. Data was collected by means of a structured questionnaire in a convenience sampling procedure. Figure 1 presents the interconnection between the development and implementation elements.

The developed SLMS consists of components from varying research fields, requiring it to be evaluated in terms of a combination of criteria. In order to evaluate student satisfaction with the new SLMS, the following criteria were adopted form Almarashdeh et al. (2018):

- Information Quality (IQ) that refers to the output provided and can be measured in terms of accuracy and reliability 
- System Quality (SQ) can be measured in terms of availability and response time

- The perceived Ease of Use (EOU) refers to how user friendly the system is to the end-users

- Perceived Usefulness (PU) refers to the expectation of the users in terms of the effect it will have on their work performance

- The User Satisfaction (US) of the students can be measured according to their expectation of the system and the subsequent confirmation of the expectations

- The Net Benefit (NB) of a LMS is measured according to its efficiency and indicates the balance of the positive and negative effects on a user

During development of the SLMS, the following criteria needed to be considered in terms of an actionsupport recommender system (Jameson et al., 2014):

- $\quad$ The information provided must be relevant (IR) to assist the user in making informed decisions
- The content must be displayed to the user so that it is effectively interpreted, processed and acted (IPA) upon

- Mechanical tasks like computations (MC) must be done by the system

- The system must correctly advise (UA) the user on the proper action(s) to take

- The domain must be designed (DD) in such a way that the user can make an informed decision

- The system must evaluate (DE) the different decisions that a user can make

The criteria were translated into a survey that users completed upon using the SLMS. The survey constructs and their relations to the criteria are shown in Table 1. Feedback was provided to students in spreadsheet format throughout the semester and the SLMS was only presented to students after finalization of the semester test. Therefore, system quality (SQ) in terms of availability and response time, was not evaluated by means of the survey.

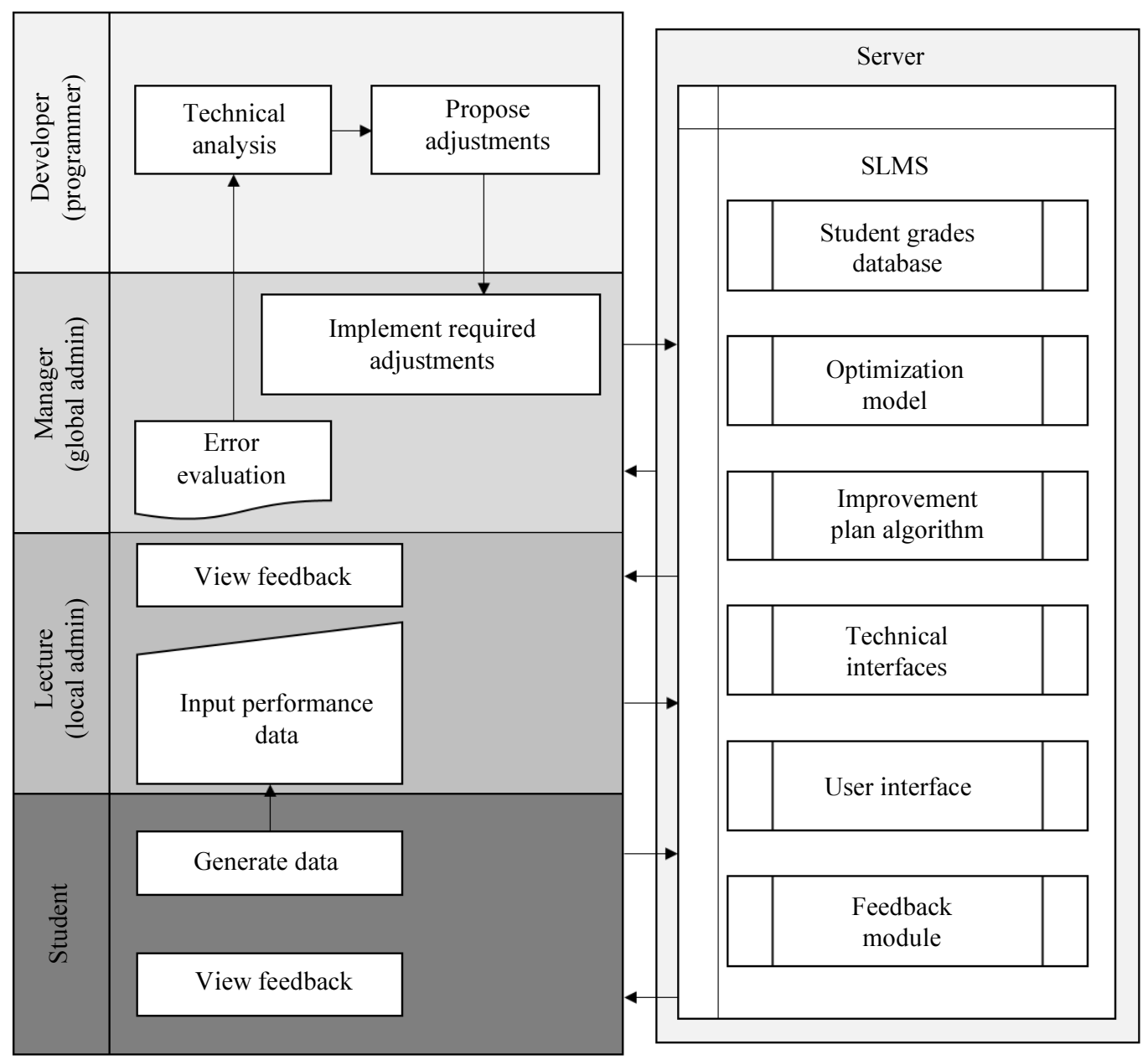

Fig. 1: Interaction between the relevant elements 
Table 1: User survey

\begin{tabular}{|c|c|}
\hline Criteria & Constructs \\
\hline NB, IQ & $\begin{array}{l}\text { 1. The feedback system keeps me informed on my current academic standing (current marks and level of } \\
\text { participation) throughout the semester. }\end{array}$ \\
\hline $\mathrm{NB}, \mathrm{UA}$ & $\begin{array}{l}\text { 2. The feedback system provides me with effective improvement goals (how much I can still improve on } \\
\text { my participation mark). }\end{array}$ \\
\hline NB, UA, IQ & $\begin{array}{l}\text { 3. The feedback system effectively provides for specific targets (which assessments to complete and what } \\
\text { marks to achieve in them) that will help me to make informed decisions on how and when to participate in } \\
\text { academic activities throughout the semester. }\end{array}$ \\
\hline PU, IR, US & 4. The feedback system will help me to monitor my progress throughout the semester. \\
\hline PU, IPA & 5. The feedback system will motivate me to participate in upcoming academic activities. \\
\hline PU, IPA, UA & $\begin{array}{l}\text { 6. The feedback system will provide me with essential tools to self-regulate my academic conduct } \\
\text { participation in upcoming activities). }\end{array}$ \\
\hline EOU, IPA & 7. The feedback system is easy to use. \\
\hline EOU. IPA & 8. The feedback delivered is easy to understand and interpret. \\
\hline IR, US & 9. I will use the feedback system throughout a semester. \\
\hline DD & $\begin{array}{l}\text { 10. I prefer to receive feedback in: } \\
\text { a) Spreadsheet format as provided up to now; } \\
\text { b) The new SLMS; or } \\
\text { c) Both formats. }\end{array}$ \\
\hline
\end{tabular}

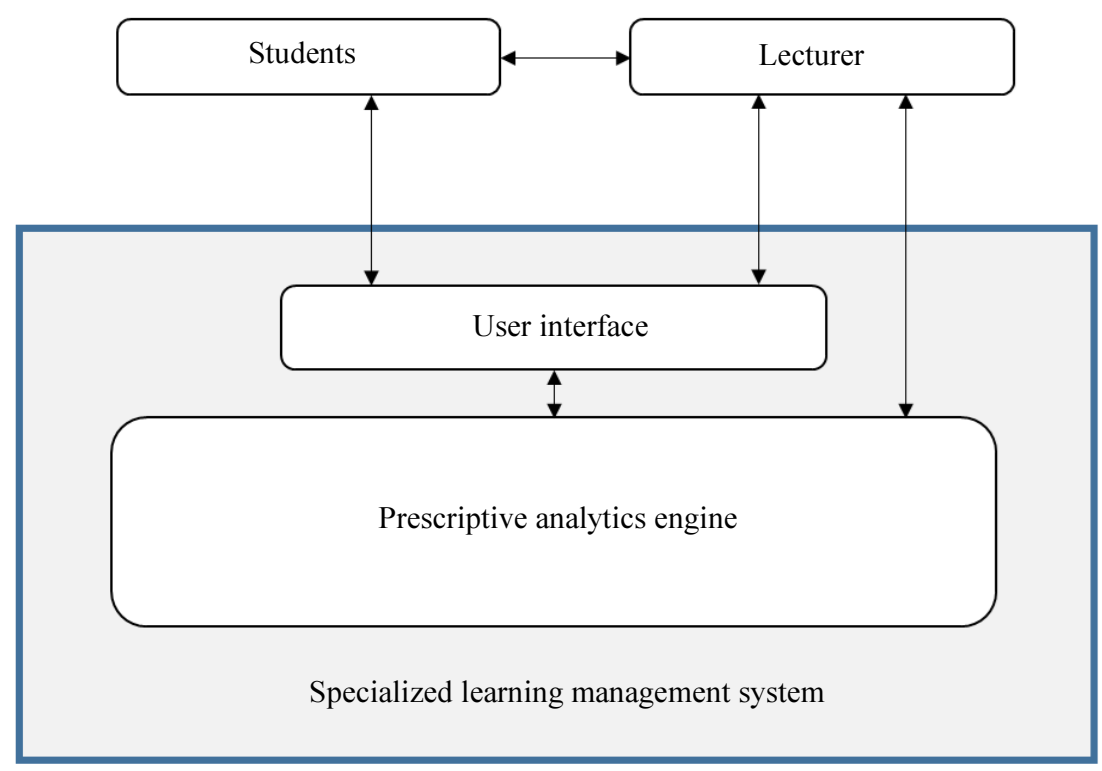

Fig. 2: Structure of the SLMS

The Mechanical tasks (MC) such as computations were done by implementing the prescriptive analytics engine as described by Van der Merwe et al. (2018b) and was subsequently not evaluated in the survey. Respondents were invited to indicate their level of agreement with statements 1-9 on a Likert scale ranging from one (totally disagree) to seven (totally agree). For evaluation of the Domain Design (DD), students were asked to select which feedback format between the normal spreadsheet format and the SLMS they preferred to use. Decision Evaluation (DE) is automatically performed when the SLMS is used because the minimum and maximum improvement options that can be implemented are both provided to a student so that an informed decision can be made.
As existing grading systems are commonly stored in spreadsheet format, the SLMS was developed with a user front-end application in MS-Excel. Figure 2 shows the main components of the SLMS and the interaction between them.

After processing the student data, the information that needs to be provided to the students as feedback has to be structured in such a manner that the students can understand its meaning and correctly interpret the actions that they are suggested to take. To this end, a graphical user interface was designed to import the processed data and provide it to the students in the correct format.

Normally, during the course of a semester, a lecturer requires the students to take different forms of assessments. The grades for these assessments are then used 
to create an academic performance profile for each student. It was found in a pilot-study that receiving feedback in spreadsheet format could easily result in misinterpretation of the information (Van der Merwe et al., 2016). An example of such feedback, with additional explanations, is shown in Fig. 3.

The SLMS gives students access to their grades either in the typical spreadsheet format, or they can view an interpretation of their performance profiles as shown in Fig. 4.

To effectively advise a student on options towards academic improvement, the system uses an algorithmic approach discussed by Van der Merwe et al. (2018b) to determine viable possibilities. The algorithm considers a semester plan typically provided by a lecturer and creates a decision tree with all of the possible participation scenarios for a student. The decision tree and a student's existing performance status are then used to calculate the maximum and minimum possible improvement on an existing participation mark. Figure 5 shows an example of an improvement plan for a student in a module where there are: One class test, two practical assignments and four attendances remaining for a semester.

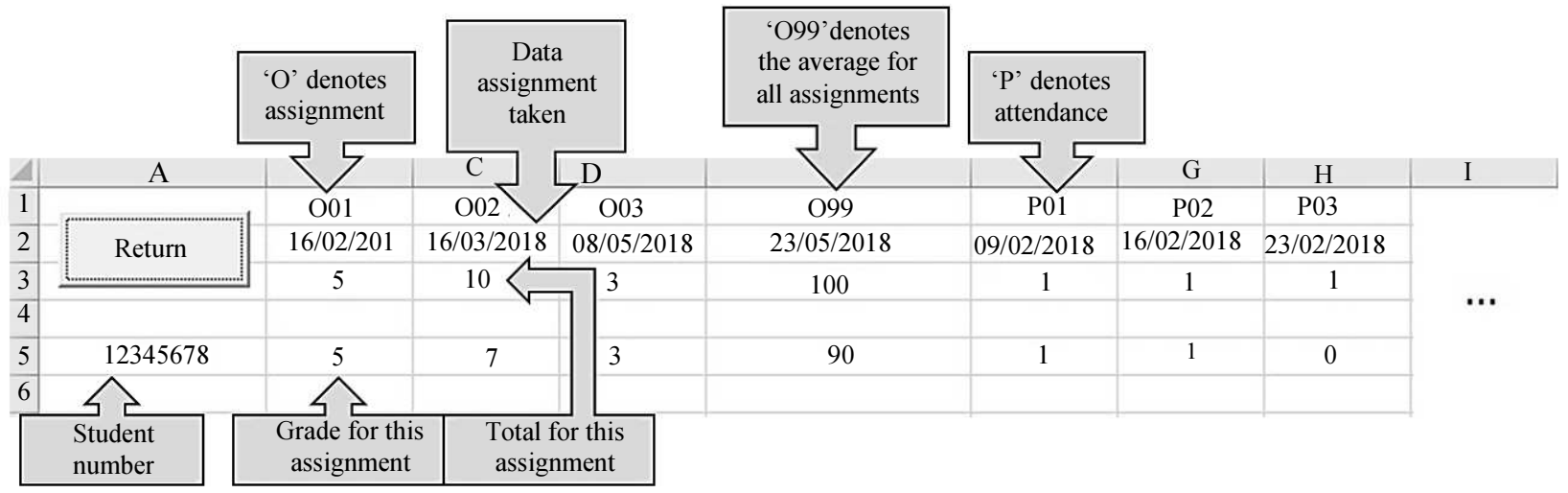

Fig. 3: Example of a student performance report in spreadsheet format

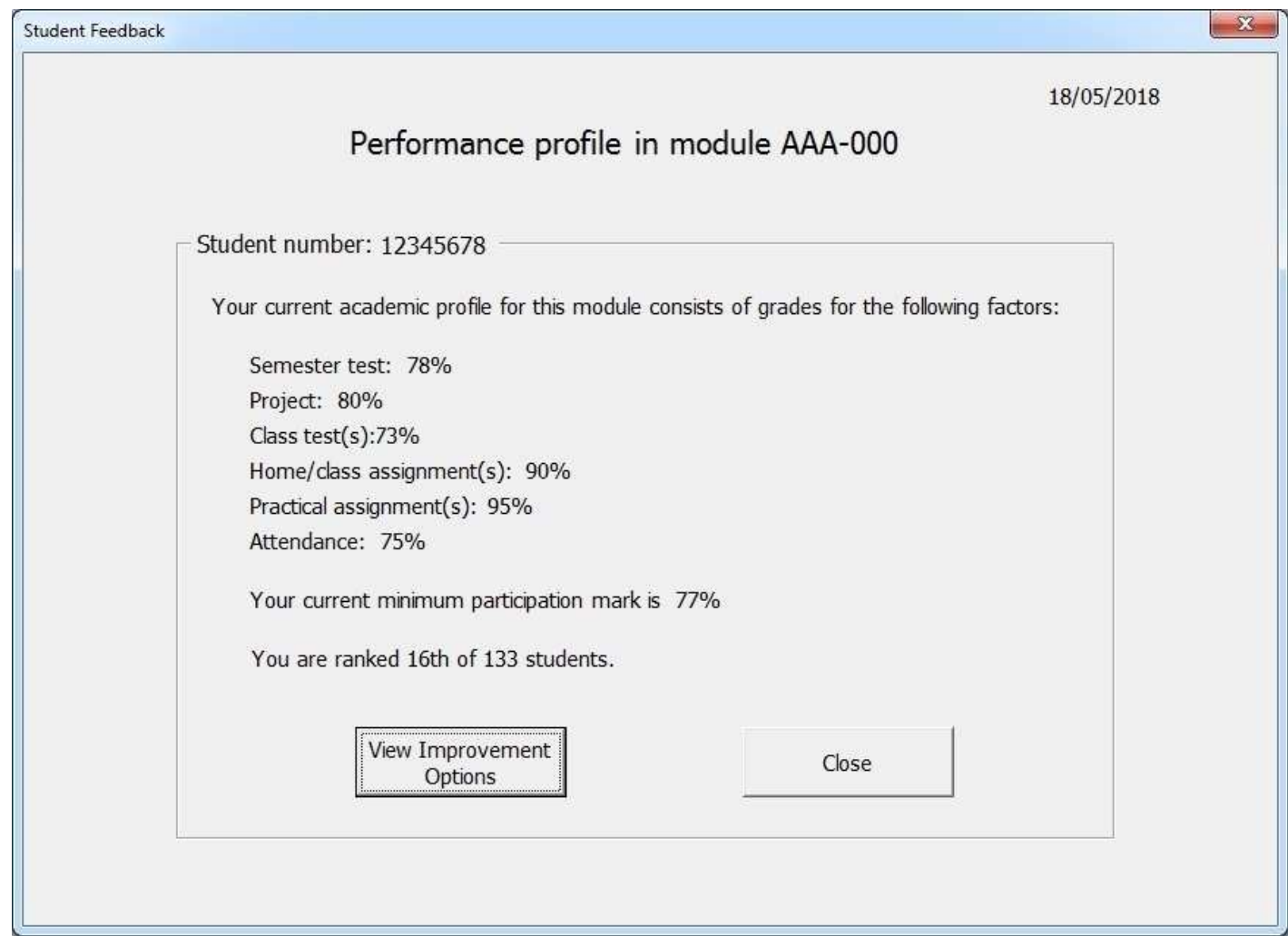

Fig. 4: Example academic performance profile 


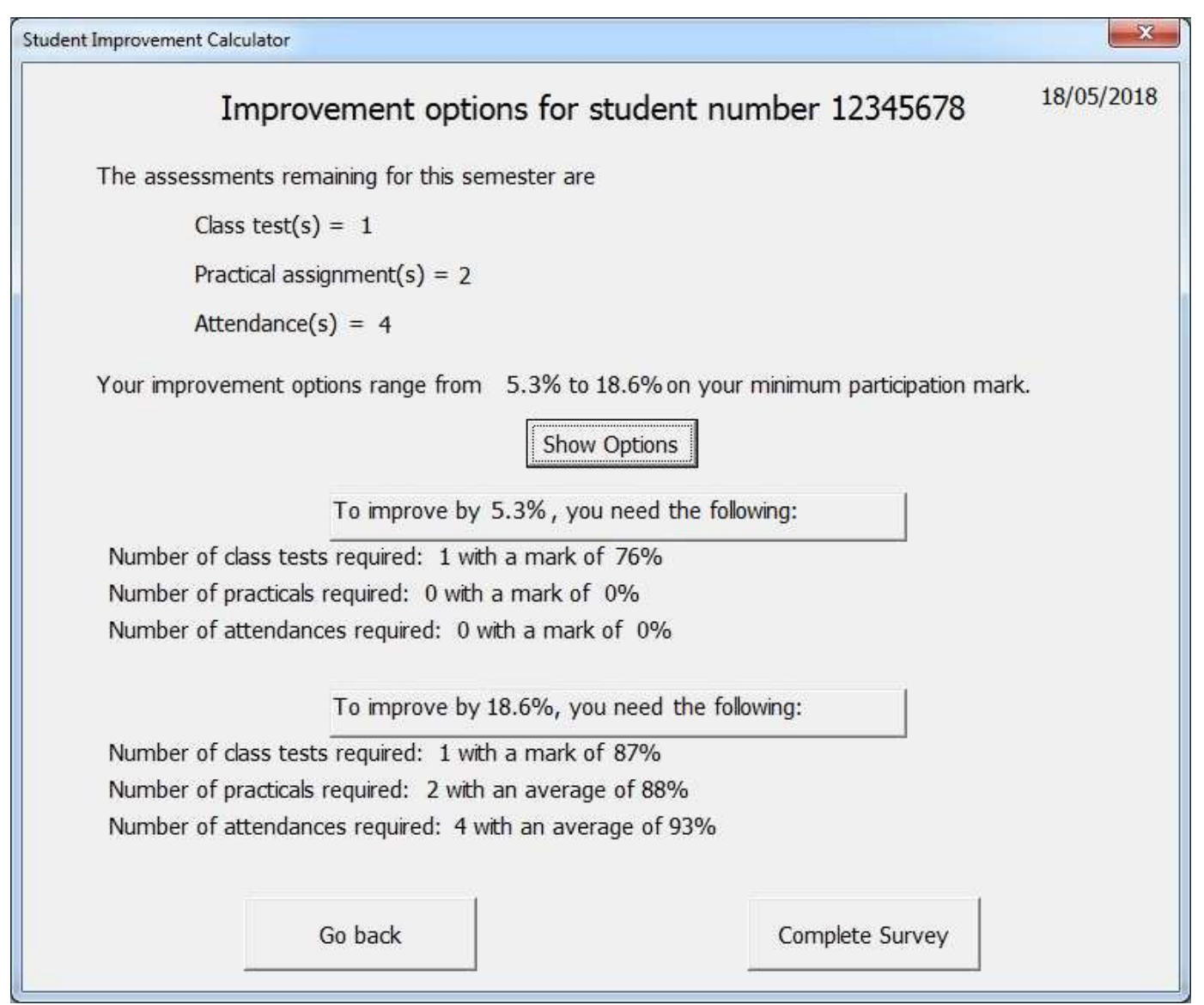

Fig. 5: Example improvement plan calculated in terms of assessments remaining for a semester

In the example scenario, the student's participation mark will improve only if the student achieves a grade of $76 \%$ in the next class test. The system shows the minimum and the maximum level of assessment participation and the required grade(s).

The student survey contains constructs created from literature and adapted for evaluation of an SLMS and was detailed in this section. The measurement instrument as well as the SLMS developed in this study was also presented. The field test environment and implementation along with the survey results are discussed in the next section.

\section{Field Testing}

The developed SLMS was presented to students enrolled in a third year module at an institution for tertiary education during a contact session and they were invited to partake in the field test by using the system and completing the created survey. They were provided with their grades and participation marks via spreadsheets throughout the semester and the SLMS was provided to them only after completion of the semester test. The semester test is a formative assessment typically taken in the middle of a semester and constitutes the largest sum towards the final participation mark. Students were asked to use the SLMS and compare it with the existing spreadsheet feedback process.

The students reacted favorably towards the SLMS, openly commenting that they found the system very helpful and informative as opposed to the normal spreadsheet feedback. There were 129 students enrolled in the module and a total of 97 (75\%) survey responses were received upon completion of the field test.

The most promising result found after evaluating the responses was that $93 \%$ (students who responded with a six or seven on the Likert scale) indicated that they would use the SLMS throughout the semester if implemented early on. Figure 6 shows how satisfied students felt towards utilizing the SLMS across an entire semester. The results show that the students view the SLMS and its prescriptive capabilities to be useful. One of the students mentioned that having access to a layout of the remaining assessments for a semester as well as an individual improvement plan can assist students in balancing their academic workload better. A total of $86 \%$ of the students commented that the SLMS was easy to use with $82 \%$ indicating that it was easy to understand and interpret. 


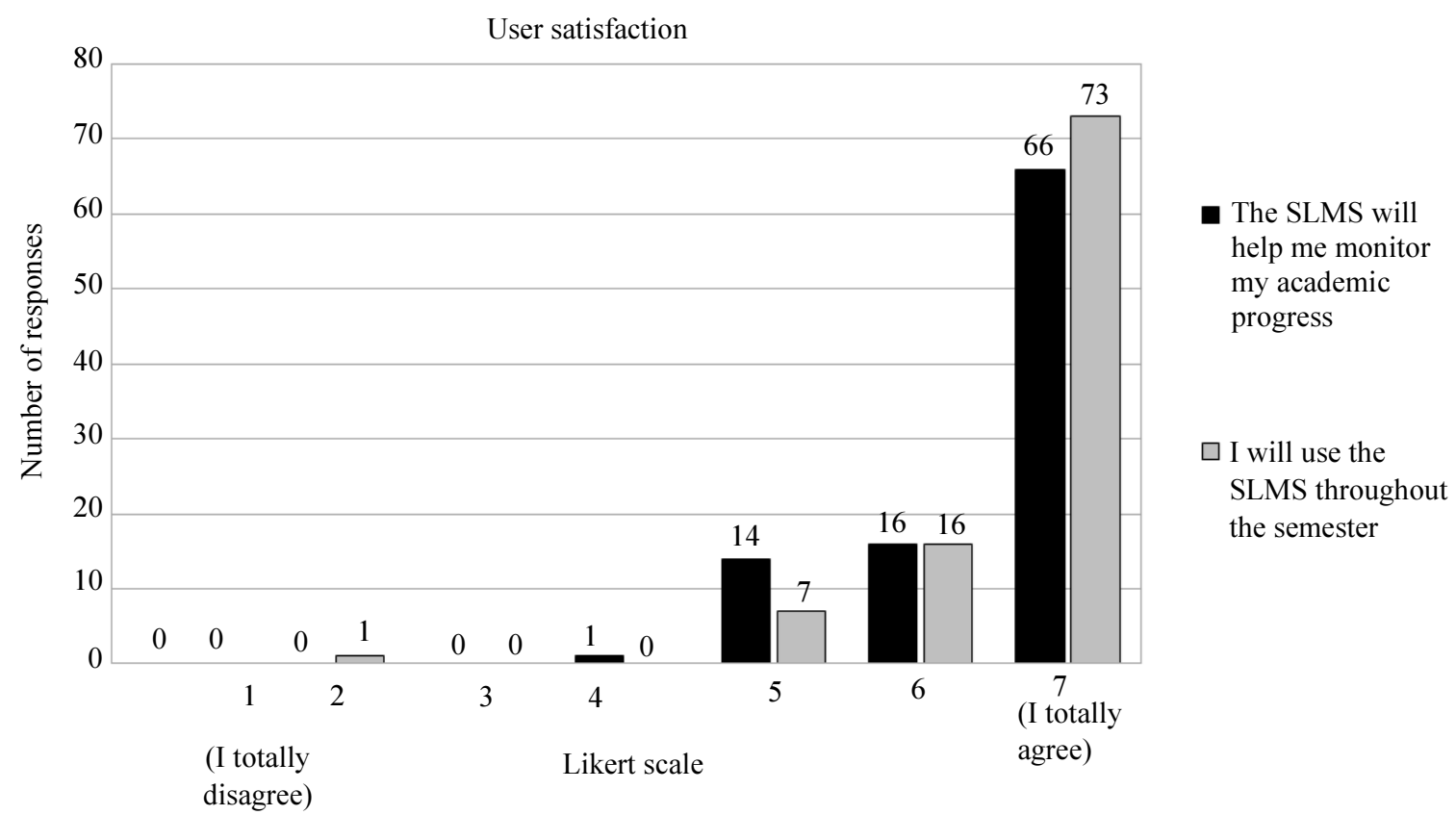

Fig. 6: User satisfaction with the SLMS

Preference of SLMS over spreadsheet feedback

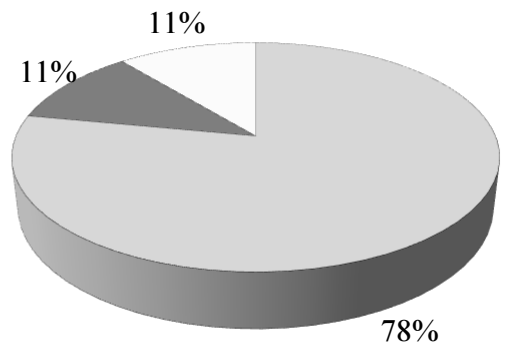

$\square$ The new feedback system

Spreadsheet format (as one previously)

$\square$ Both

Fig. 7: Student preferences on feedback format

When the question was posed as to which feedback format the students preferred, $78 \%$ of the respondents indicated that they wanted to receive academic feedback by means of the SLMS. Moreover, $11 \%$ felt that they wanted to use the SLMS and still have access to the spreadsheet containing the complete set of grades and the remaining $11 \%$ preferred feedback in the normal spreadsheet format only. Dissemination of these results is illustrated in Fig. 7.

The response averages for the remaining factors are shown in Fig. 8. The figures show that the students consider the information provided to be relevant to the point that they will be effectively assisted to make informed decisions regarding their future participation in academic activities. It can also be deduced that they approve of the newly-developed user interface and feel that the feedback provided will be correctly interpreted.

Although obtaining high ratings in the survey, the Information Quality (IQ), Net Benefit (NB) and User Advisor (UA) factors scored slightly lower than the other factors. It is believed that this is due to the survey being conducted so close to the end of the semester which meant that students had little opportunity to implement the advice given to them by the system.

This section contained a discussion on the implementation of the developed SLMS in a tertiary education environment. This was followed by an outline of the results obtained in the accompanying user survey. The next section intends to discuss the research contributions that this study provides as well as special features unique to the SLMS.

\section{Discussion}

LMSs are widely used for, among others, administration, tracking and delivering educational resources, whereas SLMSs are created for very specific purposes presenting an ideal platform for supplying students with academic feedback. The following research contributions are presented by this study.

A unique feature that this study contributes towards is the time-dependent improvement plans provided to individual students. 


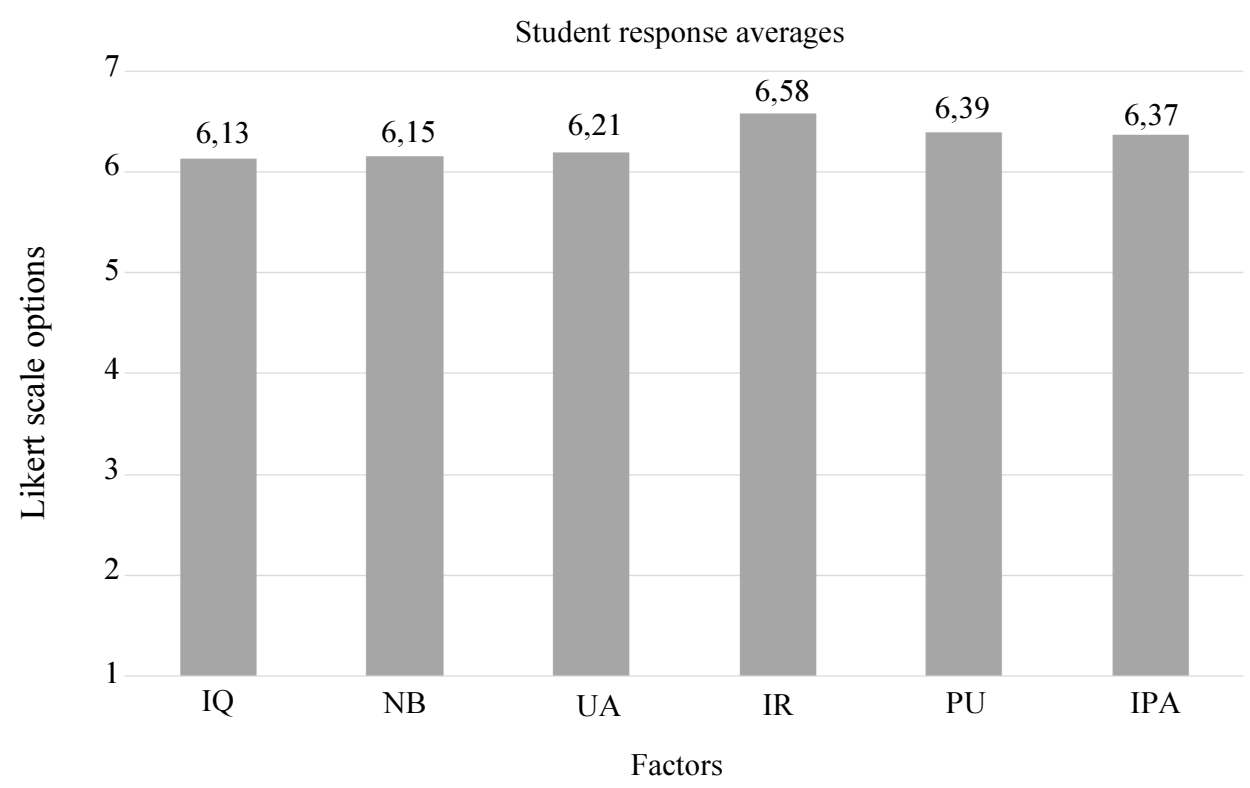

Fig. 8: Response averages for the remaining factors detailed in Table 1

During an investigation into existing academic feedback methods, little evidence was found of dynamic and individualized improvement plans being presented to students. The SLMS constructed in this study utilizes specialized analytical methods to address this problem. Furthermore, the system will improve student retention by assisting lecturers to identify atrisk students and address academic-related problems at an early stage in the semester.

The academic feedback provided is dynamic and presented in real-time. The prescriptive analytical engine incorporated in the SLMS implements a mathematical modelling technique and algorithm and can be used as frequently as needed to create updated academic performance profiles for each individual student. This also means that feedback is available to students at all times and they can access it as frequently as required.

The SLMS provides comprehensive academic feedback. Research has shown that students need additional information for them to cultivate a responsibility towards their academic conduct. This study addresses this issue by providing students with information related to their current academic performance level. The individualized improvement plans generated by the SLMS are unique in that they provide each student with an exclusive and timedependent set of instructions on how to improve upon his/her current academic status by considering the remaining assessment opportunities for a specific module. The results have shown that students believe the developed SLMS will help them to better monitor their progress and regulate their studies.
The research further offers empirical confirmation that most students prefer to receive feedback via an SLMS that provides supplementary information on their academic performance than from normal spreadsheets. It further shows that most students readily accepted the structured manner in which the new system provided the feedback. The feedback gives students the opportunity to personally identify learning problems they may have which can help to build their self-confidence and improve their ability to regulate their own progress. The respondents further indicated that the SLMS was easy to use and that the resulting feedback was easily interpreted. This contrasts with the students' reactions towards the normal spreadsheet format in that they frequently returned to the lecturer with enquiries about result interpretations.

Providing an academic ranking can assist students in monitoring their performance in relation to their peers, without detailed knowledge of their grades. The student ranking can also assist a lecturer to identify which students need additional instruction and the individualized improvement plans will furthermore make it simple for a lecturer to guide a student towards learning success. A lecturer implementing an SLMS like the one developed in this study will further benefit from its use by having instant online access to the academic performance profiles of all the students enrolled in a particular course. The feedback can likewise be accessed by students online from any platform, providing potential for use in distance learning courses.

Although the SLMS was readily accepted by the responding students, some remaining challenges need to be further investigated: 
- The mathematical modelling techniques and algorithmic approach utilized to create the student performance profiles, were discussed in a related study (Van der Merwe et al., 2018b) and are implemented here as black-box tools. This means that in general a lecturer has limited control over the implicit and explicit constructs inside the mathematical model and algorithm. Expanding the system to allow lecturers such access needs to be investigated

- Although the system is simple to use and to publish to students, combining these methods into a single system will facilitate central organization and processing of student data. Incorporation of the system into an existing LMS therefore remains a future challenge

- Although the number of students who prefer to receive feedback in the normal spreadsheet format was a minority, it means that some of the information they would like to see is not included in the new SLMS. As a detailed layout of their grades for individual assessments is available, it can only mean that they want to be able to compare grades obtained in individual assessments to those of their peers. This issue needs to be considered for possible future improvements on the SLMS

This section provided a brief discussion on research contributions made by the development and evaluation of the SLMS. It further stated some issues that can be addressed in future developments. The next section will close the paper by providing some concluding remarks.

\section{Conclusion}

It was stated earlier that combining different methodological approaches can increase the value of learning analytics towards the quality of learning. Academic feedback in a module presented at tertiary level is key to assisting students with regulating their studies, as well as lecturers with improving student retention rates. The main concern of this study was to develop, implement and evaluate a system that utilizes mathematical modelling and algorithmic techniques as prescriptive analytics to provide students with academic status reports, improvement plans and specific actions to take towards the recommended plans. The SLMS would provide not only timely academic performance feedback to students in a tertiary educational environment but also act as an action-recommender system by providing them with discrete advice as to which actions to take towards improved learning and performance.

This study was performed according to a research and development cycle published by Darmawan et al. (2018) and the developed SLMS was evaluated for user satisfaction and acceptance, as well as its effectiveness as an action-recommender system. The literature study investigated research, related to the use of an LMS and a recommender system and established criteria by which similar SLMSs could be evaluated. The SLMS was consequently implemented and evaluated for several criteria contributing to the level of LMS acceptance and action-recommender system effectiveness.

A field test was performed by implementing the SLMS in a tertiary module after which a survey was conducted to measure user response in terms of the identified factors. The results showed that the SLMS conforms to the attributes essential to an action-recommender system and was favorably accepted by the target users.

Although the developed SLMS currently acts as a stand-alone application for any tertiary module, it is being considered to incorporate the system into an existing LMS. Such a combined system will improve the general security of users, overall system integrity and enable access to the system on mobile devices. Future research and development on refining the system for mobile devices, is underway.

\section{Author's Contributions}

Annette van der Merwe: Design of the research plan, development of the SLMS, writing the manuscript.

Tiny du Toit: Supervisor of research, revising themanuscript.

Hennie Kruger: Supervisor of research, revising the manuscript.

\section{Ethics}

This article is original work and has not been submitted for publication elsewhere. Respondents participated voluntarily with the knowledge that they were contributing to a research paper. The study has been approved by the scientific committee at a tertiary education institution. The authors have read and approved the manuscript.

\section{References}

Almarashdeh, I., M.K. Alsmadi, G. Jaradat, A. Althunibat and S.A. Albahussain et al., 2018. Looking inside and outside the system: Examining the factors influencing distance learners satisfaction in learning management system. J. Comput. Sci., 14: 453-465. DOI: 10.3844 /jcssp.2018.453.465

Beck, R.C., 2004. Motivation: Theories and principles. 5th Edn., Prentice, Upper Saddle River, ISBN-10: 013111445X.

Bersin, J., 2015. Talent management software market surges ahead. Forbes.

Carroll, R.A. and C.C. St. Peter, 2017. Proportion of available points predicts student attendance in college courses. Psychol. Record, 67: 61-69.

DOI: $10.1007 / \mathrm{s} 40732-016-0207-y$ 
Daniel, B., 2015. Big data and analytics in higher education: Opportunities and challenges. Brit. J. Educ. Technol., 46: 904-920. DOI: 10.1111/bjet.12230

Darmawan, D., H. Kartawinata and W. Astorina, 2018. Development of Web-based Electronic Learning System (WELS) in improving the effectiveness of the study at vocational high school "Dharma Nusantara". J. Comput. Sci., 14: 562-573. DOI: $10.3844 /$ jcssp.2018.562.573

De Freitas, S., D. Gibson, C. Du Plessis, P. Halloran and E. Williams et al., 2015. Foundations of dynamic learning analytics: Using university student data to increase retention. Brit. J. Educ. Technol., 46: 1175-1188. DOI: 10.1111/bjet.12212

Di Domenico, S.I. and M.A. Fournier, 2015. Able, ready and willing: Examining the additive and interactive effects of intelligence, conscientiousness and autonomous motivation on undergraduate academic performance. Learn. Individual Diff., 40: 156-162. DOI: $10.1016 /$ j.lindif.2015.03.016

Dietz-Uhler, B. and J. Hurn, 2013. Using learning analytics to predict (and improve) student success: A faculty perspective. J. Interactive Online Learn., 12: 17-26.

Du Toit, J.V., 2015. Using participation marks to manage, motivate and inform on academic progress. Proceedings of the Conference for Outstanding Teaching/Learning and Innovative Technology Use. Potchefstroom, South Africa.

Ellis, R.A., F. Han and A. Pardo, 2017. Improving learning analytics-combining observational and selfreport data on student learning. Educ. Technol. Society, 20: 158-169.

Fındık-Coşkunçay, D., N. Alkış and S. Özkan-Yıldırım, 2018. A structural model for students' adoption of learning management systems: An empirical investigation in the Higher Education context. Educ. Technol. Society, 21: 13-27.

Garcia, T., 1996. Self-regulation: An introduction. Learn. Individual Diff., 8: 161-163. DOI: 10.1016/S1041-6080(96)90012-6

Hattie, J. and H. Timperley, 2007. The power of feedback. Rev. Educ. Res., 77: 81-112. DOI: $10.3102 / 003465430298487$

Hernández-Lara, A., A. Perera-Lluna and E. SerradellLópez, 2018. Applying learning analytics to students' interaction in business simulation games. The usefulness of learning analytics to know what students really learn. Comput. Human Behav. DOI:10.1016/j.chb.2018.03.001

Jameson, A., B. Berendt, S. Gabrielli, F. Cena and C. Gena et al., 2014. Choice architecture for humancomputer interaction. Foundat. Trends HumanComput. Interact., 7: 1-235.

DOI: $10.1561 / 1100000028$
Jepson, A. and W.G. Ryan, 2018. Applying the Motivation, Opportunity, Ability (MOA) model and Self-Efficacy (S-E) to better understand student engagement on undergraduate event management programs. Event Manage., 22: 271-285.

DOI: $10.3727 / 152599518 X 15173356116718$

Kaklauskas, A., E.K. Zavadskas, M. Seniut, V. Stankevic and J. Raistenskis et al., 2013. Recommender system to analyze student's academic performance. Expert Syst. Applic., 40: 6150-6165. DOI: 10.1016/j.eswa.2013.05.034

Lee, J., 2018. Feedback on feedback: Guiding student interpreter performance. Int. J. Translat. Interpret. Res., 10: 152-170. DOI: 10.12807/ti.110201.2018.a09

Lin, S., 2015. SaaS learning management system: Is your LMS truly SaaS? eLearning Industry.

Massingham, P. and T. Herrington, 2006. Does attendance matter? An examination of student attitudes, participation, performance and attendance. J. Univ. Teach. Learn. Pract., 3: 82-103.

Patall, E.A., R.R. Steingut, A.C. Vasquez, S.S. Trimble and K.A. Pituch, 2018. Daily autonomy supporting or thwarting and students' motivation and engagement in the high school Science classroom. J. Educ. Psychol., 110: 269-288. DOI: $10.1037 / \mathrm{edu} 0000214$

Rock, M.L., 2005. Use of strategic self-monitoring to enhance academic engagement, productivity and accuracy of students with and without exceptionalities. J. Positive Behav. Intervent., 7: 3-17. DOI: $10.1177 / 10983007050070010201$

Schumacher, C.I., 2017. Features students really expect from learning analytics. Comput. Human Behav., 78: 397-404. DOI: 10.1016/j.chb.2017.06.030

Sclater, N., A. Peasgood and J. Mullan, 2016. Learning analytics in higher education: A review of UK and international practice. Jisc, Bristol.

Siponen, M. and A. Tsohou, 2018. Demistifying the influential IS legends of positivism. J. Assoc. Inform. Syst., 19: 600-67. DOI: $10.17705 / 1$ jais.00503

Suthers, D. and K. Vebert, 2013. Learning analytics as a "middle space". Proceedings of the International Conference on Learning Analytics and Knowledge, Apr. 8-13, ACM Press, New York, pp: 1-4. DOI: $10.1145 / 2460296.2460298$

Van der Merwe, A., J.V. Du Toit and H.A. Kruger, 2018a. Architecture for personalized academic feedback. Proceedings of the WEI International Academic Conference Proceedings, (ACP' 18), Vienna, Austria, pp. 94-111.

Van der Merwe, A., H.A. Kruger and J.V. Du Toit, 2018b. Mathematical modelling for academic performance status reports in learning analytics. ORiON, 34: 31-64. DOI: 10.5784/34-1-582 
Van der Merwe, A., J.V. du Toit and H.A Kruger, 2016. Student ranking by means of non-linear mathematical optimization of participation marks. Manage. Sci., 8:113-119.

Yulianto, B., H. Prabowo, R. Kosala and M. Hapsara, 2018. Implementation of learning analytics in MOOC by using artificial unintelligence. J. Comput. Sci., 14: 317-323. DOI: 10.3844/jcssp.2018.317.323

\section{Appendix A: Linear Programming Model (Van der Merwe et al., 2018b)}

The average participation mark for each student is calculated from the maximum and minimum determined by solving this linear programming model:

$$
\begin{aligned}
& \text { subject to } \mid \sum_{j=1}^{n} w_{j}=1, \\
& l \leq w_{j} \leq u, \\
& w_{j} \geq w_{j-1}, \\
& l, u \geq 0, \\
& w_{j} \geq \varepsilon,
\end{aligned}
$$$$
\text { Maximise / minimise } p_{\alpha}=\sum_{j=1}^{n} y_{\alpha j} w_{j} \text {, }
$$

where, $w_{j}$ is the weight assigned to factor $j, y_{\alpha j}$ is the calculated average for factor $j$ of student $\alpha$ and $n$ is the number of factors.

\section{Appendix B: Algorithm for Determining Improvement Plan (Van der Merwe et al., 2018b)}

The algorithm shown uses the current factor (different types of assessments) averages for a student at a specific time in the semester, a detailed layout of the remaining assessments and the percentage improvement $\delta$ required. Using truth table layout principles, a set of possible participation scenarios for the remainder of the semester is created. For $s$ assessment opportunities, this will result in $2^{s}$ scenarios. The assessment plan is then used to eliminate participation scenarios that are impossible within the time constraints stipulated.

\begin{tabular}{ll}
\hline & $\bar{y}=\left\{y_{1}, \ldots, y_{n}\right\}$ is an array representing the \\
& current factor averages for a student in $n$ factors, \\
Input: & $A=\left\{\bar{a}_{1}, \ldots, \bar{a}_{s}\right\}$ an array denoting the remaining \\
& $s$ assessment sessions and $\delta$ the required \\
& percentage factor improvement. \\
Output: & An array $\overline{x_{r}}$ with $r$ possible improvement \\
& scenarios.
\end{tabular}

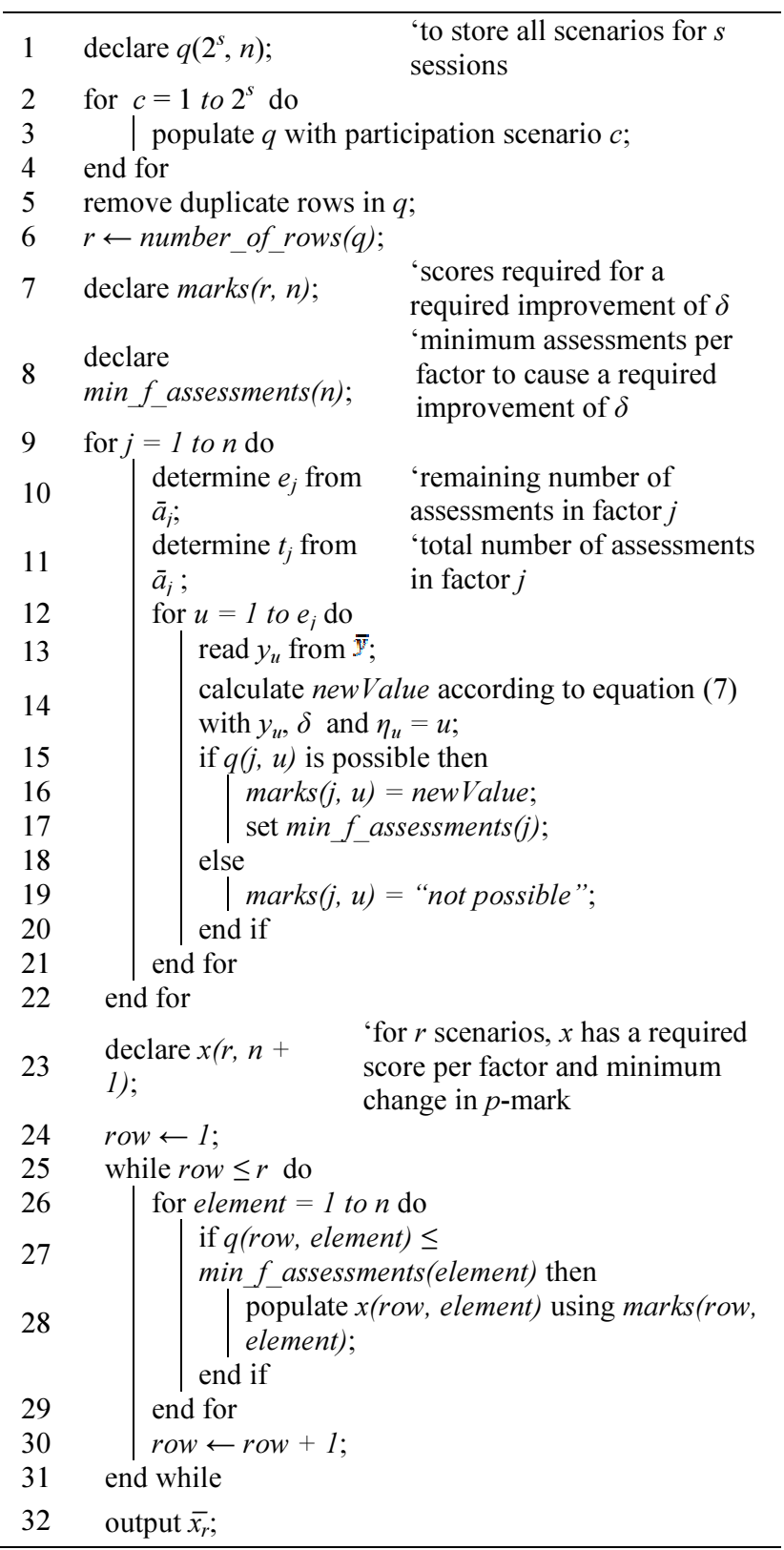

The scores required in upcoming assessments to produce the desired improvement in line 14 is calculated according to:

$\operatorname{marks}_{j}=\frac{\delta t_{j}+e_{j} y_{\alpha j}}{\eta_{j}}$,

where, marks $_{j}$ represents the grade a student should achieve in the next $\eta_{j}$ assessments of factor $j, t_{j}$ is the total number of assessments in the term for factor $j, e_{j}$ is the remaining number of assessments for factor $j$ and $y_{\alpha j}$ is the current factor average in factor $j$ for student $\alpha$. 